\title{
Medically assisted reproduction and the risk of preterm birth: a case-control study using data from the Quebec Pregnancy Cohort
}

\author{
Jessica Gorgui MSc, Odile Sheehy MSc, Jacquetta Trasler MD PhD, William Fraser MD MSc, \\ Anick Bérard PhD
}

\section{Abstract}

Background: The use of fertility treatments has been growing over the past decade, but these treatments are not without risk. We aimed to quantify the risk of preterm birth associated with the use of ovarian stimulators (OS) and assisted reproductive technologies (ART) overall and by type of fertility treatment.

Methods: We conducted a case-control analysis of data from the Quebec Pregnancy Cohort. We included singleton pregnancies ending in a live birth during the time when Quebec operated a universal reimbursement program for assisted reproduction (2010-2015). Fertility treatments were defined dichotomously, and pregnancies resulting from spontaneous conception were used as the reference. We categorized fertility treatments into subgroups: ovarian stimulators alone, ART alone and OS and ART combined. Preterm birth was defined as birth before 37 weeks' gestation. We estimated odds ratios (ORs) for the association between type of assisted reproduction and preterm birth using generalized estimating equation models and adjusted ORs for potential confounders.

Results: A total of 57624 pregnancies were included in the study. During the study period, 2055 pregnancies were conceived through the use of OS, ART or both: 419 involved OS alone, 150 involved ART alone and 1486 involved both OS and ART. When we adjusted for potential confounders, conception with OS, ART or both was associated with an increased risk of preterm birth (adjusted OR 1.46, 95\% confidence interval [Cl] 1.25-1.72, 182 exposed cases). All types of assisted reproduction were associated with an increased risk of preterm birth compared with pregnancies conceived spontaneously (OS alone: adjusted OR 1.47, 95\% $\mathrm{Cl}$ 1.04-2.07; ART alone: adjusted OR 1.76, 95\% Cl 1.01-3.06; OS and ART combined: adjusted OR 1.43, 95\% Cl 1.19-1.73). Use of OS or ART or both was associated with an increased risk of late, moderate and extremely preterm birth (extremely preterm birth: adjusted OR 2.39, 95\% $\mathrm{Cl} 1.30-4.39)$.

Interpretation: Compared with pregnancies conceived spontaneously, pregnancies conceived through the use of OS, ART or both were associated with a $46 \%$ increased risk of preterm birth. Physicians should advise patients of the increased risks of late, moderate and extremely preterm birth so that they can make informed choices.

T nfertility affects approximately $30 \%$ of women, ${ }^{1}$ and $8 \%-20 \%$ of couples report having difficulty conceiving. ${ }^{2-5}$ Fertility treatments are defined as procedures of medically assisted reproduction, including in vitro fertilization and ovarian stimulation. ${ }^{6,7}$ Assisted reproductive technologies (ART) are procedures that include the handling of oocytes and sperm or of embryos to induce a pregnancy. ${ }^{6}$

Over 5 million children have been conceived through in vitro fertilization worldwide. ${ }^{8}$ Data from the Canadian Assisted Reproduction Technologies Register reported in 2011 indicate that the use of ART has steadily increased, having tripled in the preceding decade; ${ }^{9} 27356$ cycles were reported in 2011 across Canada. ${ }^{9}$

In 2010, Quebec became the first Canadian province to implement a universal reimbursement program for assisted reproduction. The program aimed to reduce the frequency of pregnancies with multiple embryos through the practice of single embryo transfers, and to help couples with subfertility and infertility to conceive. ${ }^{10}$ The program was halted in 2015 following an increase in related health care expenditures that was higher than expected. The rate of assisted conceptions increased substantially with this program: $2.0 \%$

Competing interests: None declared.

This article has been peer reviewed.

Correspondence to: Anick Bérard, anick.berard@umontreal.ca CMAJ Open 2020. DOI:10.9778/cmajo.20190082 
of all Quebec pregnancies resulted from in vitro fertilization in $2012 / 13$ versus $1.2 \%$ in $2009 / 10 .^{10}$

Evidence-based findings showed that children conceived with ART were at an increased risk of major congenital malformations and low birth weight compared with children who had been spontaneously conceived. ${ }^{11-17}$ However, most studies failed to observe this association within groups exposed to specific assisted methods and specifically among singletons. Studies focused on in vitro fertilization or inseminations or combined non-in vitro methods together, which has limited clinical implications. ${ }^{16-18}$

Use of ART increases the risk of pregnancy with more than 1 embryo, ${ }^{19}$ which is associated with an increased risk of preterm birth risk, ${ }^{20}$ suggesting that pregnancy involving more than 1 embryo is a mediator in the association. Preterm birth is a major risk factor for infant morbidity and mortality. ${ }^{21}$ It is associated with substantial burdens for health care systems and caregivers. ${ }^{21}$ In Canada, the prevalence of preterm birth is $7.8 \%$, which is lower than in the United States (10\%). ${ }^{22}$

Given the increasing rates of conception with ART and the repercussions of preterm birth, our primary aim was to quantify the risk of preterm birth associated with assisted conception in singletons while the universal reimbursement program was active in Quebec. Our secondary aim was to quantify this association specifically among women exposed to ovarian stimulators alone, ART alone, and both.

\section{Methods}

\section{Data sources}

The Quebec Pregnancy Cohort (QPC) is a population-based cohort with prospective data collection linked to 3 provincial databases: Régie de l'assurance maladie du Québec (RAMQ), which includes information on medical services, procedures and pharmaceutical services (drug name, duration, dosage); Maintenance et exploitation de données pour l'étude de la clientèle hospitalière (MED-ÉCHO), which archives information on hospital admissions (diagnostic codes from the International Classification of Diseases, 9th Revision, and International Classification of Diseases and Related Health Problems, 10th Revision [ICD-9, ICD-10], interventions, procedures); and the database of the Institut de la statistique du Québec, which contains sociodemographic information as well as data on birth weight and gestational age. These databases were linked through a unique patient-encrypted identifier.

The QPC includes data on all pregnancies of women covered by the public prescription drug insurance plan between January 1998 and December 2015. Data on mothers and children following the end of pregnancy are also collected. Prospective follow-up data are available from at least 1 year before the first day of gestation, during pregnancy and until December 2015. We defined the first day of gestation as the first day of the last menstrual period validated against ultrasound measures in patients' charts. ${ }^{23}$ The QPC and its data sources have been described in more detail by Bérard and Sheehy. ${ }^{23}$

\section{Study design and population}

We conducted a case-control analysis within the QPC. No sampling was performed, as all eligible pregnancies were considered.

Pregnancies were analyzed if they met the following inclusion criteria: the pregnancy resulted in a singleton live birth and the conception date was between Aug. 5, 2010, and Nov. 15, 2015. Multiple pregnancies were excluded, as these pregnancies are a known risk factor for preterm birth and a possible mediator in the relationship between assisted reproduction and preterm birth. ${ }^{19}$ We used 2010-2015 as the study time period given that the assisted reproduction reimbursement program was active only during that time; Chaabane and colleagues quantified the risk of preterm birth with assisted reproduction in Quebec before 2010. ${ }^{19}$ We excluded pregnancies exposed to medications known to be fetotoxic (Appendix 1, Supplemental Table S1, available at www. cmajopen.ca/content/8/1/E206/suppl/DC1). ${ }^{24,25}$

\section{Exposure}

Assisted reproduction was defined as having occurred if there was a billing code for ART (e.g., in vitro fertilization) or if at least 1 prescription was filled for ovarian stimulators (leuprolide, citrorelix, ganirelix, follitropin, gonadotropins, gonadorelin, progesterone, estradiol, clomiphene) within 2 months before and 1 month after the first day of gestation (Appendices 2 and 3, Supplemental Tables S2 and S3, available at www.cmajopen.ca/content/8/1/E206/suppl/DC1). The time window before the first day of gestation was chosen to ensure that the pregnancy in question resulted from exposure to an ART or ovarian stimulators or both; we extended the time window to 1 month after the first day of gestation to account for late billings by physicians.

We first assessed pregnancies that involved the use of any of the fertility treatments included in the study, and then we analyzed 3 subcategories of pregnancies: use of ovarian stimulators alone, use of ART alone and use of both ovarian stimulators and ART (at least 1 prescription and 1 billing code). Spontaneously conceived pregnancies served as the reference. A variety of prescription fillings (e.g., for antidepressants, antibiotics) have been validated against maternal reports of taking the prescribed medication in the QPC (positive and negative predictive values $>87 \%) .{ }^{26}$ It is possible that patients may have filled a prescription but not taken the treatment; however, given that ovarian stimulators are prescribed to patients with infertility who wish to become pregnant, we believe that we measured our exposure appropriately.

\section{Outcome}

Preterm birth was defined as a birth occurring before 37 completed weeks of gestation, on the basis of the World Health Organization's definition (ICD-10). We identified pregnancies that ended with a preterm birth using data on gestational age in the MED-ECHO database validated against ultrasound measures in patients' charts as well as the database of the Institut de la statistique du Québec. ${ }^{26}$ Preterm birth was categorized as late preterm (34-37 weeks' gestation), moderate 
preterm (32-34 weeks' gestation), very preterm (28-32 weeks' gestation) and extremely preterm ( $<28$ weeks' gestation). ${ }^{28}$ Furthermore, gestational age, which defines our outcome, has been validated. ${ }^{27}$

\section{Covariates}

We selected potential covariates on the basis of their association with assisted reproduction and preterm birth a priori: (a) sociodemographic variables on the first day of gestation including maternal age, receipt of social assistance and area of residence (urban v. rural, as defined by the Institut de la statistique du Québec); (b) previous pregnancy in the year before the first day of gestation, ending in delivery, abortion or miscarriage; (c) maternal history of chronic comorbidities during the year before the first day of gestation, namely hypertension, diabetes, depression or anxiety, asthma, thyroid disorders, epilepsy, coagulopathies, infections and use of medications for conditions other than those described; and (d) obesity and smoking measured during the year before the first day of gestation and during pregnancy, as these variables are probably reported at prenatal visits and are unlikely to change during gestation. All covariates were measured using ICD-9 and ICD-10 codes and data on filled prescriptions that were related to the studied health conditions (Appendix 4, Supplemental Table S4, available at www.cmajopen.ca/ content/8/1/E206/suppl/DC1).

\section{Statistical analyses}

We performed descriptive statistical analyses to compare term with preterm birth with respect to exposure to ART and ovarian stimulators and covariate status. The unit of analysis was a pregnancy. We performed $t$ tests and $\chi^{2}$ tests for continuous and categorical variables, respectively. Standardized mean differences were also calculated between groups to assess clinically significant differences. Pregnancy complications (premature rupture of membranes, placental dysfunction and preterm labour [Appendix 5, Supplemental Table S5, available at www.cmajopen.ca/content/8/1/E206/suppl/DC1]) were compared between groups.

We calculated absolute risks as well as crude and adjusted odds ratios (ORs) with $95 \%$ confidence intervals (CIs) to estimate the association between preterm birth and conception using ART or ovarian stimulators compared with spontaneous conception using 2 generalized estimating equation models: (a) exposure to ART and ovarian stimulators as the dependent variable and (b) preterm birth as the dependent variable to assess both different levels of exposure to ART and ovarian stimulators and different categories of preterm birth. Adjustments were performed to account for potential confounding variables identified above.

To assess the impact of ART and ovarian stimulators on the severity of preterm birth, we performed analyses by categories of preterm birth (late, moderate, very and extreme). Additionally, to take into account patients' underlying subfertility or infertility, we estimated the association between categories of assisted reproduction (use of stimulators alone, use of ART alone and use of both) and preterm birth.
Lastly, we performed sensitivity analyses for a subcohort of women exposed to ART and ovarian stimulators to account for potential confounding by the underlying indication for the use of ART and ovarian stimulators, namely subfertility and infertility. By restricting the analysis to this subcohort, we were able to assess if the association between use of ART and ovarian stimulators and preterm birth is independent of subfertility and infertility. Statistical analyses were performed using SAS version 9.2 (SAS Institute Inc.).

\section{Ethics approval}

The study was approved by the Quebec Data Access Agency and the Research Ethics Board of the Centre hospitalier universitaire Sainte-Justine. The linkage between the databases on which the QPC is based was authorized by the Commission d'accès à l'information du Québec.

\section{Results}

Overall, 57624 singleton livebirth pregnancies met the inclusion criteria and were considered for analyses, of which 3677 $(6.4 \%)$ ended in preterm birth (Figure 1). A total of 2055 $(3.6 \%)$ of the pregnancies were conceived through the use of ovarian stimulators and ART: 419 (20.4\%) involved ovarian stimulators alone, 150 (7.3\%) involved ART alone and 1486 $(72.3 \%)$ involved both. Specifically, $182(5.0 \%)$ pregnancies in the preterm delivery group and $1873(3.5 \%)$ pregnancies in the term delivery group were conceived through the use of ART and ovarian stimulators.

Women who had preterm deliveries were more likely than women who gave birth at term to be recipients of social assistance, which is a known risk factor for preterm birth (Table 1). Women delivering preterm were more likely to have depression or anxiety and to have had a previous pregnancy within the 12 months before the first day of gestation than women who gave birth at term, although these differences were not clinically significant (standardized mean difference < 0.10) (Table 1). There were no differences between these 2 groups of women with respect to complications during the current pregnancy (e.g., preterm labour) or with respect to patterns of health care service utilization, defined as followup appointments with an obstetrician, general practitioner or family physician, hospital admissions and visits to emergency departments (Table 1).

Accounting for potential confounders, we found that use or ART or ovarian stimulators or both was significantly associated with an increased risk of preterm birth (adjusted OR 1.46, 95\% CI 1.25-1.72, 182 exposed cases) when compared with spontaneous conceptions (Table 2). This translates into an absolute preterm birth risk of $6.71 \%$ among spontaneous conceptions and $9.72 \%$ among those exposed to ART or ovarian stimulators or both (Appendix 6, Supplemental Table S6, available at www.cmajopen.ca/content/8/ 1/E206/suppl/DC1).

When we compared conceptions that involved the use of ART or ovarian stimulators or both with spontaneous conceptions, we identified statistically significant associations 


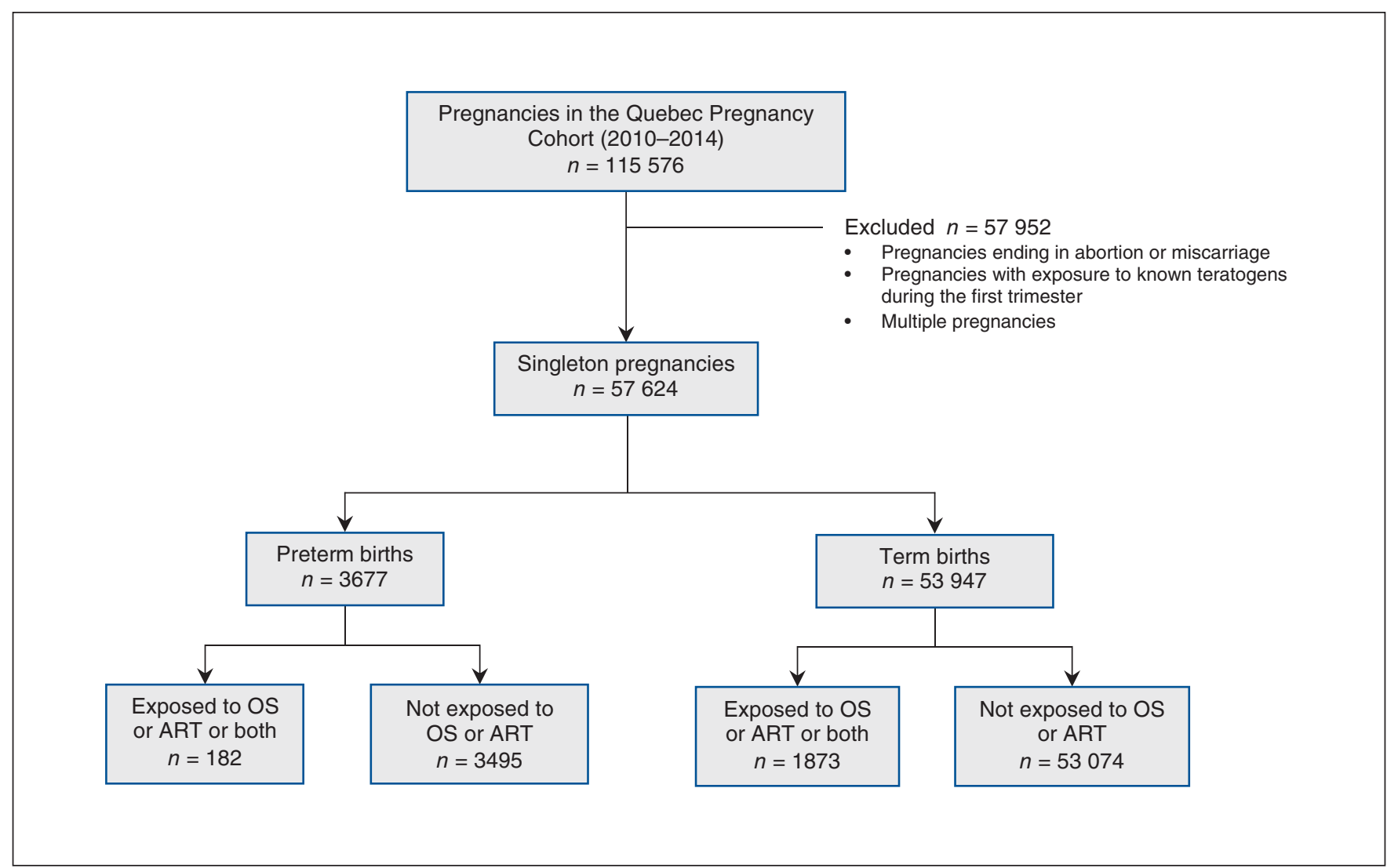

Figure 1: Flow chart of the selection process for the study population. ART = assisted reproductive technologies, OS $=$ ovarian stimulators.

between all types of assisted reproduction and preterm birth (ovarian stimulators alone: adjusted OR 1.47, 95\% CI 1.04-2.07, 38 exposed cases; ART alone: adjusted OR 1.76, 95\% CI 1.01-3.06, 15 exposed cases; both ovarian stimulators and ART: adjusted OR 1.43, 95\% CI 1.19-1.73, 129 exposed cases) (Table 2).

We observed a trend across preterm birth categories, which indicates the severity of the outcome. Use of ovarian stimulators or ART or both was significantly associated with an increased risk of late (adjusted OR 1.36, 95\% CI 1.13-1.63, 134 exposed cases), moderate (adjusted OR 1.61, 95\% CI 1.03-2.51, 20 exposed cases) and extremely preterm birth (adjusted OR 2.39, 95\% CI 1.30-4.39, 12 exposed cases) (Table 3).

To address confounding by indication, we performed a sensitivity analysis in which we restricted our study cohort to pregnancies of women exposed to ovarian stimulators or ART or both $(n=2055)$. Results showed no difference between groups (Table 4).

\section{Interpretation}

Use of ovarian stimulators or ART or both was associated with an increased risk of preterm birth in Quebec, translating into a nearly $10 \%$ prevalence of preterm birth among children conceived in this manner, compared with about $7 \%$ in the overall Quebec population. We observed a gradually increasing association across preterm birth subcategories, suggesting a higher risk for severe preterm birth among pregnancies that involved assisted reproduction.

Studies have demonstrated that pregnancies conceived via assisted reproduction are at an increased risk for preterm birth. ${ }^{17,29-31}$ Our results are consistent with the literature, including the findings of a cohort study $(n=2474195)$ involving women who underwent in vitro fertilization in the US. ${ }^{32}$ Compared with spontaneous conceptions, in vitro fertilization increased the risk of preterm birth risk by $36 \%$ to $133 \% .{ }^{17,18,32}$ Women exposed to ovarian stimulators and assisted inseminations had a $16 \%$ higher preterm birth risk than women who conceived spontaneously; this finding was not significant but it is consistent with our results. ${ }^{17}$

Luke and colleagues subcategorized preterm birth to look at the association in very early (22-27 weeks' gestation) and early preterm birth (22-32 weeks' gestation). ${ }^{32}$ They found clinically and statistically significantly increased risks (48\% to $52 \%$ ) among women who conceived with in vitro fertilization compared with women who conceived spontaneously. ${ }^{32}$ Although these risks are lower than ours, they reported similar estimates among subfertile women, defined as women undergoing stimulation or assisted insemination or both. ${ }^{32}$ This difference is probably due to the fact that we pooled all forms of assisted reproduction in the analysis by preterm birth categories, whereas Luke and colleagues observed the effects of in vitro fertilization and of ovarian stimulators and inseminations 


\section{Table 1 (part 1 of 2): Characteristics of the study population}

\begin{tabular}{|c|c|c|c|c|}
\hline \multirow[b]{2}{*}{ Characteristic } & \multicolumn{2}{|c|}{ No. $(\%)$ of pregnancies ${ }^{*}$} & \multirow[b]{2}{*}{$\begin{array}{c}\text { Standardized } \\
\text { mean } \\
\text { difference† }\end{array}$} & \multirow[b]{2}{*}{$\begin{array}{c}p \\
\text { valueł }\end{array}$} \\
\hline & $\begin{array}{c}\text { Term delivery } \\
(\geq 37 \mathrm{wk}) \\
n=53947\end{array}$ & $\begin{array}{l}\text { Preterm delivery } \\
\begin{array}{c}(<37 \mathrm{wk}) \\
n=3677\end{array}\end{array}$ & & \\
\hline \multicolumn{5}{|l|}{ Pregnancy characteristics } \\
\hline Pregnancies conceived spontaneously & $52074(96.5)$ & $3495(95.1)$ & -0.07 & \\
\hline $\begin{array}{l}\text { Pregnancies conceived through use of OS and } \\
\text { ART }\end{array}$ & $1873(3.5)$ & $182(5.0)$ & 0.07 & $<0.001$ \\
\hline OS alone & $381(0.7)$ & $38(1.0)$ & 0.03 & \\
\hline ART alone & $135(0.2)$ & $15(0.4)$ & 0.03 & \\
\hline OS and ART combined & $1357(2.5)$ & $129(3.5)$ & 0.06 & $<0.001$ \\
\hline \multicolumn{5}{|c|}{ Maternal and child sociodemographic characteristics§ } \\
\hline \multicolumn{5}{|l|}{ Maternal } \\
\hline Maternal age, yr, mean \pm SD & $29.14 \pm 5.6$ & $29.23 \pm 6.0$ & -0.02 & $<0.001$ \\
\hline \multicolumn{5}{|l|}{ Maternal age, yr } \\
\hline$<25$ & $12096(22.4)$ & $865(23.5)$ & 0.03 & \\
\hline 25-35 & 32077 (59.5) & $2047(55.7)$ & -0.08 & \\
\hline $35-40$ & $7931(14.7)$ & $586(15.9)$ & 0.03 & \\
\hline$\geq 40$ & $1843(3.4)$ & $179(4.9)$ & 0.07 & $<0.001$ \\
\hline Recipient of social assistance & $9848(18.2)$ & $997(27.1)$ & 0.21 & $<0.001$ \\
\hline Urban dweller & $44667(82.8)$ & $3008(81.8)$ & -0.03 & 0.12 \\
\hline \multicolumn{5}{|l|}{ Child } \\
\hline Sex, male & $27581(51.1)$ & $2038(55.4)$ & 0.09 & $<0.001$ \\
\hline Birth weight, $g$, mean \pm SD & $3401.90 \pm 455.56$ & $2412.44 \pm 648.78$ & 2.10 & $<0.001$ \\
\hline Pregnancies conceived spontaneously & $3402.15 \pm 455.33$ & $2418.47 \pm 643.11$ & & \\
\hline $\begin{array}{l}\text { Pregnancies conceived through use of } \\
\text { OS or ART or both }\end{array}$ & $3394.13 \pm 462.45$ & $2296.56 \pm 741.81$ & & \\
\hline \multicolumn{5}{|l|}{ Maternal comorbidities $\rrbracket$} \\
\hline Diabetes & $1536(2.8)$ & $124(3.4)$ & 0.03 & 0.07 \\
\hline Hypertension & $1118(2.1)$ & $88(2.4)$ & 0.02 & 0.19 \\
\hline Obesity & $1270(2.4)$ & $104(2.8)$ & 0.03 & 0.07 \\
\hline Asthma & $4771(8.8)$ & $358(9.7)$ & 0.03 & 0.07 \\
\hline Epilepsy & $619(1.2)$ & $53(1.4)$ & 0.03 & 0.11 \\
\hline Smoking & $1054(2.0)$ & $81(2.2)$ & 0.02 & 0.29 \\
\hline Infection & $15847(29.4)$ & $1076(29.3)$ & 0.00 & 0.89 \\
\hline Thyroid disease & $3123(5.8)$ & $236(6.4)$ & 0.03 & 0.12 \\
\hline Depression or anxiety & $6912(12.8)$ & $513(14.0)$ & 0.03 & 0.05 \\
\hline Coagulopathy & $221(0.4)$ & $22(0.6)$ & 0.03 & 0.09 \\
\hline Previous pregnancy & $6382(11.8)$ & $477(13.0)$ & 0.03 & 0.04 \\
\hline Delivery & $2175(4.0)$ & $140(3.8)$ & & \\
\hline Abortion & $2609(4.8)$ & $199(5.4)$ & & \\
\hline Miscarriage & $1598(3.0)$ & $138(3.8)$ & & \\
\hline \multicolumn{5}{|l|}{ No. of any other medications used ${ }^{\star *}$} \\
\hline 0 & $19735(36.6)$ & $1292(35.1)$ & -0.09 & \\
\hline 1 & 10529 (19.5) & $753(20.5)$ & 0.02 & \\
\hline 2 or 3 & $12980(24.1)$ & $889(24.2)$ & 0.00 & \\
\hline$\geq 4$ & $10703(19.8)$ & 743 (20.2) & 0.01 & 0.28 \\
\hline
\end{tabular}


Table 1 (part 2 of 2): Characteristics of the study population

\begin{tabular}{|c|c|c|c|c|}
\hline \multirow[b]{2}{*}{ Characteristic } & \multicolumn{2}{|c|}{ No. $(\%)$ of pregnancies* } & \multirow[b]{2}{*}{$\begin{array}{l}\text { Standardized } \\
\text { mean } \\
\text { difference } \dagger\end{array}$} & \multirow[b]{2}{*}{$\begin{array}{c}p \\
\text { valuef }\end{array}$} \\
\hline & $\begin{array}{c}\text { Term delivery } \\
(\geq 37 \mathrm{wk}) \\
n=53947\end{array}$ & $\begin{array}{l}\text { Preterm delivery } \\
\qquad \begin{array}{l}(<37 \mathrm{wk}) \\
n=3677\end{array}\end{array}$ & & \\
\hline \multicolumn{5}{|l|}{ Pregnancy complications } \\
\hline Premature rupture of membranes & $2994(5.6)$ & $222(6.0)$ & 0.02 & 0.21 \\
\hline Placental dysfunction & $280(0.5)$ & $26(0.7)$ & 0.02 & 0.13 \\
\hline Preterm labour & $526(1.0)$ & $46(1.2)$ & 0.03 & 0.10 \\
\hline Bleeding & $1291(2.49)$ & $105(2.9)$ & 0.03 & 0.08 \\
\hline \multicolumn{5}{|l|}{ Utilization of health care services } \\
\hline Follow-up by obstetricianł‡ & $31066(57.6)$ & $2121(57.7)$ & 0.002 & 0.91 \\
\hline $\begin{array}{l}\text { Follow-up by general practitioner or family } \\
\text { physicianł‡ }\end{array}$ & $13354(24.8)$ & $891(24.2)$ & -0.01 & 0.48 \\
\hline $\begin{array}{l}\text { Hospital admission and/or visit to emergency } \\
\text { department§§ }\end{array}$ & $20725(38.4)$ & $1399(38.0)$ & -0.01 & 0.66 \\
\hline \multicolumn{5}{|c|}{ 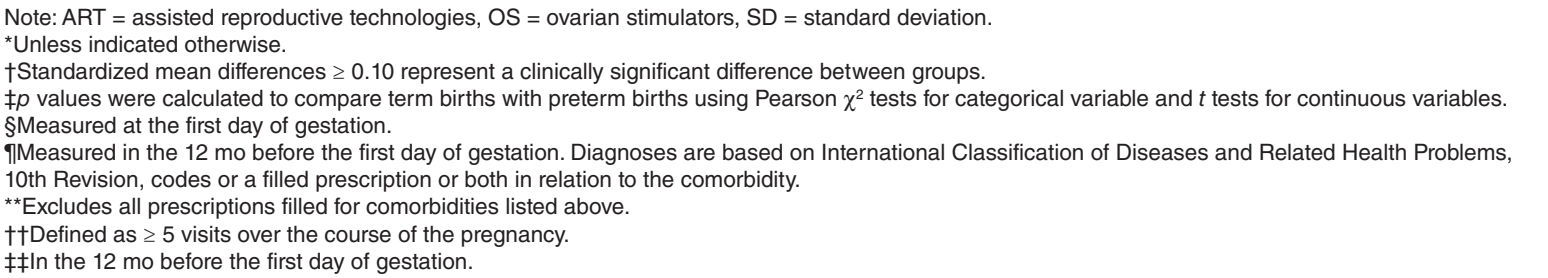 } \\
\hline
\end{tabular}

Table 2: Risk of preterm birth, by category of assisted reproduction

\begin{tabular}{|c|c|c|c|c|}
\hline \multirow[b]{2}{*}{ Category } & \multicolumn{2}{|c|}{ No. (\%) of pregnancies } & \multirow[b]{2}{*}{$\begin{array}{c}\text { Crude OR } \\
(95 \% \mathrm{Cl})\end{array}$} & \multirow[b]{2}{*}{$\begin{array}{l}\text { Adjusted OR* } \\
\qquad(95 \% \mathrm{Cl})\end{array}$} \\
\hline & $\begin{array}{l}\text { Term birth } \\
n=53947\end{array}$ & $\begin{array}{c}\text { Preterm birth } \\
n=3677\end{array}$ & & \\
\hline Spontaneous & $52074(96.5)$ & 3495 (95.0) & 1.00 & 1.00 \\
\hline Use of OS or ART or both & $1873(3.5)$ & $182(5.0)$ & $1.44(1.23-1.69)$ & $1.46(1.25-1.72)$ \\
\hline Use of OS alone & $381(0.7)$ & $38(1.0)$ & $1.47(1.04-2.07)$ & $1.47(1.04-2.07)$ \\
\hline Use of ART alone & $135(0.2)$ & $15(0.4)$ & $1.66(0.96-2.87)$ & $1.76(1.01-3.06)$ \\
\hline Use of both OS and ART & $1357(2.5)$ & $129(3.5)$ & $1.41(1.17-1.70)$ & $1.43(1.19-1.73)$ \\
\hline
\end{tabular}

separately. ${ }^{32}$ Of note, a within-family analysis found that adverse perinatal outcomes in the context of assisted reproduction were not entirely due to the methods themselves. ${ }^{33}$ It would be important to replicate these results when longer follow-up data become available for the QPC.

Given the complexity of assisted reproduction, biological mechanisms have not been put forward to explain findings. It has been suggested that among women who have children through assisted reproduction, there could be an increase in iatrogenic preterm births given that their pregnancies receive greater surveillance. ${ }^{32}$ However, it is unlikely that inductions or early cesarean deliveries would be occurring before 34 weeks' gestation, and therefore this could not explain our findings. It has been proposed that aging leads to vasculo-endothelial dysfunction, which would result in ovarian aging and poor response to ovarian stimulators. ${ }^{34-36}$ Ovarian dysfunction and alteration of the endothelial environment through assisted reproduction may be key players in explaining increased rates of preterm birth, independent of age and infertility. ${ }^{37}$

In the future, we plan to assess patterns of assisted reproduction use in the context of the universal health care program in Quebec. We also plan to analyze other perinatal outcomes, such as being born small for gestational age, and neurodevelopmental outcomes. 


\begin{tabular}{|c|c|c|c|}
\hline Timing of birth & $\begin{array}{l}\text { No. }(\%) \text { of } \\
\text { pregnancies that } \\
\text { involved use of OS } \\
\text { or ART or both } \\
n=2055\end{array}$ & $\begin{array}{c}\text { Crude OR } \\
(95 \% \mathrm{Cl})\end{array}$ & $\begin{array}{l}\text { Adjusted OR }{ }^{*} \\
(95 \% \mathrm{Cl})\end{array}$ \\
\hline Term birth & $1873(91.1)$ & 1.00 & 1.00 \\
\hline \multicolumn{4}{|l|}{ Preterm birth } \\
\hline Late preterm (34-37 weeks' gestation) & $134(6.5)$ & $1.34(1.12-1.59)$ & $1.36(1.13-1.63)$ \\
\hline Moderate preterm (32-34 weeks' gestation) & $20(1.0)$ & $1.57(1.01-2.42)$ & $1.61(1.03-2.51)$ \\
\hline Very preterm (28-32 weeks' gestation) & $16(0.8)$ & $1.65(1.01-2.72)$ & $1.59(0.94-2.68)$ \\
\hline Extremely preterm (< 28 weeks' gestation) & $12(0.6)$ & $2.47(1.35-4.51)$ & $2.39(1.30-4.39)$ \\
\hline
\end{tabular}

\begin{tabular}{|c|c|c|c|}
\hline Category of assisted reproduction & $\begin{array}{c}\text { No. }(\%) \text { of } \\
\text { preterm births } \\
n=182\end{array}$ & $\begin{array}{c}\text { Crude OR } \\
(95 \% \mathrm{Cl})\end{array}$ & $\begin{array}{l}\text { Adjusted OR* } \\
\quad(95 \% \mathrm{Cl})\end{array}$ \\
\hline Use of OS alone & $38(20.9)$ & 1.00 & 1.00 \\
\hline Use of ART alone & $15(1.0)$ & $1.13(0.60-2.13)$ & $1.08(0.58-2.08)$ \\
\hline Use of both OS and ART & $103(2.8)$ & $0.96(0.65-1.41)$ & $0.91(0.61-1.36)$ \\
\hline
\end{tabular}

\section{Limitations}

Although we adjusted for potential confounders, there are a number of variables that we could not take into account. Variables such as infections and premature rupture of membranes during the pregnancy are known risk factors for preterm birth and could be associated with assisted reproduction. However, we could not adjust for them as they are on the causal pathway between assisted reproduction and preterm birth. Nonetheless, we compared these variables between term and preterm births and found no differences. Thus, it is unlikely that accounting for these variables would have modified our estimates. We also cannot rule out the effects of unmeasured confounders, especially in relation to underlying infertility. Infertility is difficult to diagnose and is poorly reported, especially given that the reason for infertility is unknown in 30\% of cases. ${ }^{38}$ The definition of assisted reproduction was not validated in the QPC, but we took a conservative approach by including data from 2 months before to 1 month after the first day of gestation. The fact that QPC captures assisted reproduction provided in the public health care system could affect the generalizability of our results. However, our team has demonstrated through a validation study that women insured publicly and privately for health care had similar profiles. ${ }^{39}$

\section{Conclusion}

Conception through the use of ovarian stimulators and ART was associated with an increased risk of preterm birth, specifically late, moderate and extremely preterm birth, when compared with spontaneous conception. These results are in line with other studies involving women who undergo in vitro fertilization. When we categorized the type of fertility treatment, we found that there was an increased risk of preterm birth with the use of ovarian stimulators alone, the use of both ovarian stimulators and ART, and the use of ART, the latter yielding the highest increase in preterm birth risk.

Physicians should make patients aware of the increased risk of late, moderate and extremely preterm birth associated with fertility treatments so that they can make informed choices. Given the continuing rise in infertility and in the use of assisted reproduction methods, these results have direct clinical and public health considerations for children conceived through assisted reproduction. 


\section{References}

1. Chandra A, Copen CE, Stephen EH. Infertility and impaired fecundity in the United States, 1982-2010: data from the National Survey of Family Growth. Natl Health Stat Report 2013;(67):1-18, 1 p following 9.

2. Case AM. Infertility evaluation and management. Strategies for family physicians. Can Fam Physician 2003;49:1465-72.

3. Hull MG, Glazener CM, Kelly NJ, et al. Population study of causes, treatment, and outcome of infertility. Br Med f (Clin Res Ed) 1985;291:1693-7.

4. Oakley L, Doyle P, Maconochie N. Lifetime prevalence of infertility and infertility treatment in the UK: results from a population-based survey of reproduction. Hum Reprod 2008;23:447-50.

5. Thonneau P, Marchand S, Tallec A, et al. Incidence and main causes of infertility in a resident population $(1,850,000)$ of three French regions (19881989). Hum Reprod 1991;6:811-6.

6. Zegers-Hochschild F, Adamson GD, de Mouzon J, et al.; International Committee for Monitoring Assisted Reproductive Technology; World Health Organization. International Committee for Monitoring Assisted Reproductive Technology (ICMART) and the World Health Organization (WHO) revised glossary of ART terminology, 2009. Fertil Steril 2009;92:1520-4.

7. Gorgui J, Bérard A. Medically assisted reproduction and the risk of adverse perinatal outcomes. In: Sherriff DF, editor. Infertility, assisted reproductive technologies and hormone assays. London (UK): IntechOpen; 2019. Available: www.intechopen. com/books/infertility-assisted-reproductive-technologies-and-hormone-assays/ medically-assisted-reproduction-and-the-risk-of-adverse-perinatal-outcomes (accessed 2020 Mar. 4).

8. Bauquis C. The world's number of IVF and ICSI babies bas now reached a calculated total of 5 million. Brussels (Belgium): European Society of Human Reproduction and Embryology; 2012.

9. Gunby J. Assisted reproductive technologies (ART) in Canada: 2011 results from the Canadian ART Register (CARTR). Dorval (QC): Canadian Fertility and Andrology Society; 2011. Available: https://cfas.ca/_Library/_documents/ CARTR 2011.pdf (accessed 2017 Oct. 25).

10. Summary advisory on assisted reproduction in Quebec. Quebec: Commissaire à la santé et au bien-être; 2014

11. Chaabane S, Sheehy O, Monnier P, et al. Ovarian stimulators, intrauterine insemination, and assisted reproductive technologies use and the risk of major congenital malformations - the AtRISK Study. Birth Defects Res B Dev Reprod Toxicol 2016;107:136-47.

12. Chaabane S, Sheehy O, Monnier P, et al. Ovarian stimulation, intrauterine insemination, multiple pregnancy and major congenital malformations: a systematic review and meta-analysis - the ART_Rev Study. Curr Drug Saf 2016;11:222-61.

13. Kamath MS, Antonisamy B, Mascarenhas M, et al. High-risk of preterm birth and low birth weight after oocyte donation IVF: analysis of 133,785 live births. Reprod Biomed Online 2017;35:318-24.

14. McDonald SD, Han Z, Mulla S, et al.; Knowledge Synthesis Group. Preterm birth and low birth weight among in vitro fertilization twins: a systematic review and meta-analyses. Eur 7 Obstet Gynecol Reprod Biol 2010;148:105-13.

15. Hayashi M, Nakai A, Satoh S, et al. Adverse obstetric and perinatal outcomes of singleton pregnancies may be related to maternal factors associated with infertility rather than the type of assisted reproductive technology procedure used. Fertil Steril 2012;98:922-8.

16. Helmerhorst FM, Perquin DA, Donker D, et al. Perinatal outcome of singletons and twins after assisted conception: a systematic review of controlled studies. BM7 2004;328:261.

17. Wisborg K, Ingerslev HJ, Henriksen TB. In vitro fertilization and preterm delivery, low birth weight, and admission to the neonatal intensive care unit: a prospective follow-up study. Fertil Steril 2010;94:2102-6.

18. Cavoretto P, Candiani M, Giorgione V, et al. Risk of spontaneous preterm birth in singleton pregnancies conceived after IVF/ICSI treatment: metaanalysis of cohort studies. Ultrasound Obstet Gynecol 2018;51:43-53.

19. Chaabane S, Sheehy O, Monnier P, et al. Association between ovarian stimulators with or without intrauterine insemination, and assisted reproductive technologies on multiple births. Am 7 Obstet Gynecol 2015;213:511.e1-14.

20. Goldenberg RL, Culhane JF, Iams JD, et al. Epidemiology and causes of preterm birth. Lancet 2008;371:75-84.

21. Johnston KM, Gooch K, Korol E, et al. The economic burden of prematurity in Canada. BMC Pediatr 2014;14:93.

22. Blencowe H, Cousens S, Chou D, et al.; Born Too Soon Preterm Birth Action Group. Born too soon: the global epidemiology of 15 million preterm births. Reprod Health 2013;10(Suppl 1):S2.

23. Bérard A, Sheehy O. The Quebec Pregnancy Cohort — prevalence of medication use during gestation and pregnancy outcomes. PLoS One 2014;9:e93870.
24. Kulaga S, Zargarzadeh AH, Bérard A. Prescriptions filled during pregnancy for drugs with the potential of fetal harm. B7OG 2009;116:1788-95.

25. Koren G, Pastuszak A, Ito S. Drugs in pregnancy. $N$ Engl $\mathcal{7}$ Med 1998;338: 1128-37.

26. Zhao JP, Sheehy O, Gorgui J, et al. Can we rely on pharmacy claims databases to ascertain maternal use of medications during pregnancy? Birth Defects Res 2017;109:423-31.

27. Vilain A, Otis S, Forget A, et al. Agreement between administrative databases and medical charts for pregnancy-related variables among asthmatic women. Pharmacoepidemiol Drug Saf 2008;17:345-53.

28. Preterm birth [fact sheet]. Geneva: World Health Organization; 2018. Available: www.who.int/news-room/fact-sheets/detail/preterm-birth (accessed 2018 May 2).

29. Blondel B, Kogan MD, Alexander GR, et al. The impact of the increasing number of multiple births on the rates of preterm birth and low birthweight: an international study. Am 7 Public Health 2002;92:1323-30.

30. Chistyakova G, Gazieva I, Remizova I, et al. Risk factors vary early preterm birth and perinatal complications after assisted reproductive technology. Gynecol Endocrinol 2016;32(Suppl 2):56-61.

31. Mascarenhas M, Sunkara SK, Antonisamy B, et al. Higher risk of preterm birth and low birth weight following oocyte donation: a systematic review and meta-analysis. Eur 7 Obstet Gynecol Reprod Biol 2017;218:60-7.

32. Luke B, Brown MB, Wantman E, et al. Risk of prematurity and infant morbidity and mortality by maternal fertility status and plurality. 7 Assist Reprod Genet 2019;36:121-38.

33. Goisis A, Remes H, Martikainen P, et al. Medically assisted reproduction and birth outcomes: a within-family analysis using Finnish population registers. Lancet 2019;393:1225-32.

34. Bonamy AK, Parikh NI, Cnattingius S, et al. Birth characteristics and subsequent risks of maternal cardiovascular disease: effects of gestational age and fetal growth. Circulation 2011;124:2839-46.

35. Hastie CE, Smith GC, Mackay DF, et al. Maternal risk of ischaemic heart disease following elective and spontaneous pre-term delivery: retrospective cohort study of 750350 singleton pregnancies. Int 7 Epidemiol 2011; 40:914-9.

36. Pell JP, Smith GC, Walsh D. Pregnancy complications and subsequent maternal cerebrovascular events: a retrospective cohort study of 119,668 births. Am 7 Epidemiol 2004;159:336-42.

37. Sunkara SK, La Marca A, Seed PT, et al. Increased risk of preterm birth and low birthweight with very high number of oocytes following IVF: an analysis of 65868 singleton live birth outcomes. Hum Reprod 2015;30: 1473-80.

38. Infertility revisited: the state of the art today and tomorrow. The ESHRE Capri Workshop. European Society for Human Reproduction and Embryology. Hum Reprod 1996;11:1779-807.

39. Bérard A, Lacasse A. Validity of perinatal pharmacoepidemiologic studies using data from the RAMQ administrative database. Can 7 Clin Pharmaco 2009;16:e360-9.

Affiliations: Research Centre (Gorgui, Sheehy, Bérard), Centre hospitalier universitaire Sainte-Justine; Faculty of Pharmacy (Gorgui, Bérard), University of Montréal; Departments of Pediatrics, Human Genetics and Pharmacology, and Therapeutics and Research Institute of the McGill University Health Centre (Trasler), McGill University, Montréal, Que.; Faculty of Medicine and Health Sciences (Fraser), University of Sherbrooke, Sherbrooke, Que.

Contributors: Jessica Gorgui, Odile Sheehy and Anick Bérard contributed to the study design, data collection, analysis of data and preparation of the manuscript. Jacquetta Trasler and William Fraser contributed to data interpretation and critical review of the final document. All authors gave final approval of the version to be published and agreed to act as guarantors of the work.

Funding: This work was supported by grant no. 30962 of the Fonds de recherche du Québec -Santé (FRQS) granted to Anick Bérard and by an FRQS doctoral award granted to Jacquetta Trasler.

Supplemental information: For reviewer comments and the original submission of this manuscript, please see www.cmajopen.ca/content/8/1/ E206/suppl/DC1. 